\title{
Penentuan Harga Opsi Tipe Eropa dengan Model Binomial
}

\author{
Via Maulida ${ }^{*}$, Emy Siswanah $^{2}$, Eva Khoirun Nisa ${ }^{3}$ \\ ${ }^{1,2,3}$ Fakultas Sains dan Teknologi, UIN Walisongo Semarang \\ *viamaulida.vm@gmail.com
}

\begin{abstract}
ABSTRAK
Opsi merupakan suatu jenis kontrak yang memberikan hak kepada salah satu pihak untuk menjual atau membeli sejumlah saham pada suatu harga dan jangka waktu tertentu. Tujuan dari penelitian ini adalah untuk menentukan harga opsi call dan put tipe Eropa menggunakan model binomial $n$ langkah dan membandingkan hasil perhitungan harga opsi model binomial $n$ langkah dengan harga opsi model Black-Scholes dan harga opsi pasar. Model binomial merupakan model sederhana yang digunakan untuk menentukan harga opsi dengan mengasumsikan dua kemungkinan pergerakan harga saham yaitu harga saham akan naik atau turun. Hasil penelitian ini menunjukkan bahwa penentuan harga opsi tipe Eropa dipengaruhi oleh harga saham $\left(S_{0}\right)$, harga kontrak $(K)$, waktu jatuh tempo $(T)$, volatilitas $(\sigma)$, suku bunga $(r)$ dan parameter yang dibutuhkan untuk menghitung harga opsi yaitu peluang harga saham naik $(p)$, tingkat kenaikan harga saham $(u)$, tingkat penurunan harga saham $(d)$. Dilihat dari besar erornya, secara empiris penentuan harga opsi dengan model binomial memberikan harga yang lebih mendekati harga opsi pasar dibandingkan dengan besar eror yang dihasilkan dari harga opsi model Black-Scholes terhadap harga opsi pasar. Namun secara empiris, harga opsi yang dihasilkan oleh model binomial hampir sama dengan harga opsi yang dihasilkan oleh model Black-Scholes yang merupakan model yang telah banyak diterima di dunia keuangan. Kata kunci: Opsi Eropa, Model Binomial, Model Black-Scholes.
\end{abstract}

\section{ABSTRACT}

Option is essentially a right to buy or sell a particular stock for a predetermined period and price. The purpose to this research is to determine call and put option price European type then will be compared with the market's option price and Black-Scholes option price. Binomial model is simple models to determine option price that assumed to have two future values which are to be increasing or decreasing. The result of this research show that the determination of option price are influenced by the initial stock price $\left(S_{0}\right)$, strike price $(K)$, the maturity date $(T)$, volatility $(\sigma)$, interest rate $(r)$ and the basic parameters that are needed to be calculated to determine option price are the probability of the neutral risk ( $p)$, the level of increasing stock price (u) and the level of decreasing stock price (d). Known from the large error, empirically the determination of option price with the binomial model gives a price that is closer to the the market's option price rather than the larger error from the Black-Scholes models to the market's option price. However option price that obtained by the binomial model are almost same with the option price of Black-Scholes model. Keywords: European Option, Binomial Model, Black-Scholes Model. 


\section{PENDAHULUAN}

Investasi bertujuan untuk memperoleh keuntungan yang besar dengan biaya yang minimum. Namun untuk memperoleh keuntungan yang besar, investor harus berani menanggung resiko. Untuk meminimumkan resiko, maka berkembanglah produk-produk baru yang disebut produk derivatif. Produk derivatif berfungsi u ntuk melindungi dan meningkatkan keuntungan pada investasi yang dilakukan (Judokusumo, 2007). Salah satu dari bentuk produk derivatif adalah opsi.

Apabila investor menggunakan opsi, resiko kerugian yang besar akan menjadi kecil karena opsi memberikan hak dan bukan kewajiban kepada pemegangnya untuk menjual atau membeli sebuah finansial selama jangka waktu tertentu. Dilihat dari risiko yang ditimbulkan, kerugian yang akan dialami oleh pembeli opsi hanyalah sejumlah harga opsi yang dibayar, akan tetapi keuntungan yang mungkin didapat tidak terbatas jumlahnya (Siahaan, 2008).

Opsi adalah suatu jenis kontrak antara dua pihak, dimana satu pihak memberikan hak kepada pihak yang lain untuk membeli atau menjual saham dalam jangka waktu dan harga tertentu. Opsi dibedakan menjadi dua jenis yaitu opsi put dan opsi call. Opsi put adalah opsi yang memberikan hak kepada pemegangnya untuk menjual sejumlah tertentu saham suatu perusahaan kepada penjual opsi pada harga dan waktu tertentu. Opsi call adalah suatu tipe kontrak yang memberikan hak kepada pembeli opsi untuk membeli dari penjual opsi berupa saham tertentu pada harga dan jangka waktu tertentu (Hull, 2012).

Berdasarkan waktu jatuh temponya, opsi dapat dikelompokkan menjadi dua yaitu opsi tipe Eropa dan opsi tipe Amerika. Opsi tipe Eropa adalah opsi yang dapat dilaksanakan pada saat jatuh tempo saja, sedangkan opsi tipe Amerika adalah opsi yang dilaksanakan pada saat jatuh tempo atau sebelumnya (Hull, 2012).

Sebelum melakukan suatu kontrak opsi, sebaiknya investor mengetahui cara-cara dalam memprediksi suatu pergerakan harga saham dan meramalkan segala kemungkinan yang terjadi guna meminimalkan kerugian dan memaksimalkan keuntungan dalam melakukan kontrak opsi. Masalah yang menarik saat melakukan suatu kontrak opsi adalah bagaimana menentukan harga yang pantas dibayar oleh pembeli opsi kepada penjual opsi saat membeli sebuah opsi dari penjual opsi.

Pada tahun 1973 Fisher Black dan Mayor Scholes merumuskan model untuk penghitungan harga opsi secara analitik yang dikenal sebagai model Black-Scholes. Model Black-Scholes sangat berguna untuk menilai apakah harga opsi di pasar sudah merupakan harga yang fair bagi opsi tersebut. Apabila harga opsi yang terjadi di pasar tidak sesuai dengan harga yang dihasilkan model Black-Scholes, maka investor akan mendapat keuntungan (Tandelilin, 2017). Model Black-Scholes merupakan model yang telah banyak diterima oleh masyarakat keuangan, namun penggunaan model Black-Scholes terbatas hanya pada opsi tipe Eropa dan hanya digunakan untuk saham yang tidak membagikan deviden (Siahaan, 2008).

Pada tahun 1979 Cox, Ross and Rubinstein menyajikan suatu pendekatan numerik untuk penghitungan harga opsi yang disebut model binomial. Model binomial adalah model yang digunakan dalam penentuan harga opsi dengan mengasumsikan dua kemungkinan pergerakan harga saham di masa mendatang yaitu harga saham akan naik atau harga saham akan turun. Model binomial menyediakan hampiran diskrit untuk proses harga kontinu di bawah model Black-Scholes (Agustina, 2009). Model binomial sangat berguna untuk menentukan harga opsi 
terutama yang tidak dapat diturunkan secara analitik. Model ini menggambarkan berbagai kemungkinan jalan yang bisa diikuti harga saham sepanjang masa opsi.

Penelitian ini bertujuan untuk menentukan harga opsi call dan put tipe Eropa dengan menggunakan model binomial, kemudian hasilnya dibandingkan dengan harga opsi pasar dan harga opsi model Black-Scholes. Oleh karena itu diharapkan dari penelitian ini dapat berguna untuk menetukan harga opsi tipe Eropa dengan menyajikan model pergerakan saham yang lebih sederhana daripada model Black-Scholes, dimana model Black-Scholes menggunakan penurunan secara analitik yang lebih kompleks.

\section{METODE}

\subsection{Sumber Data}

Data yang digunakan dalam penelitian ini adalah harga saham awal $\left(S_{0}\right)$, harga kontrak $(K)$ dan data opsi call dan put pada perusahaan Caterpillar Inc. (CAT), The Walt Company (DIS), Apple Inc. (AAPL), Tesla Inc. (TSLA), dan Facebook, Inc. (FB) yang diperoleh dari http://www.finance.yahoo.com/ dengan waktu jatuh tempo 30 hari atau $T=\frac{1}{12}$ bulan $=$ 0,0833 . Suku bunga bebas resiko $(r)$ yang digunakan adalah suku bunga bank central Amerika (FED) sebesar 2,5\% yang diperoleh dari https://www.global-rates.com/interest-rates/centralbank-america/fed-interest-rate.aspx.

\subsection{Langkah Analisis Data}

Langkah-langkah analisis yang dilakukan dalam penelitian ini adalah

(1) menentukan harga opsi call dan put dengan menggunakan model binomial $n$ langkah,

(2) menentukan parameter $\mathrm{u}, \mathrm{d}$, dan $\mathrm{p}$,

(3) membandingkan hasil perhitungan harga opsi call dan put dari model binomial dengan harga opsi pasar dan harga opsi model Black-Scholes.

\section{HASIL DAN PEMBAHASAN}

\subsection{Model Binomial $\boldsymbol{n}$ Langkah}

Perhitungan harga opsi menggunakan model binomial didasarkan pada kenyataan bahwa dalam pasar bebas harga saham akan selalu berubah naik atau turun seiring perubahan waktu. Misalkan harga saham pada saat $t=0$ adalah $S_{0}$ dan pada saat $t=T$ akan naik dengan peluang $p$ menjadi $S_{u}$ atau akan turun dengan peluang $1-p$ menjadi $S_{d}$, sehingga harga opsi pada saat $t=0$ adalah $V_{0}$ dan pada saat $t=T$ akan naik menjadi $U$ atau akan turun menjadi $D$ (Aziz, 2009).

Model binomial berangkat dari suatu model pergerakan harga saham yang sederhana. Selang waktu $[0, T]$ dibagi menjadi $n$ yang sama panjang sehingga (Higham, 2004)

$$
\begin{aligned}
& \Delta t=\frac{T}{n} \\
& t_{i}=i . \Delta t \text { dimana } i=0,1, \ldots, n \\
& S_{i}=S\left(t_{i}\right) \text { adalah harga saham pada saat } t_{i}
\end{aligned}
$$


Asumsi-asumsi yang digunakan dalam model binomial adalah (Aziz, 2009):

1. Setiap periode waktu $\Delta t$ harga saham $S$ dapat naik menjadi $S_{u}$ atau turun menjadi $S_{d}$ dengan $0<d<u<1$. Parameter $u$ dan $d$ masing-masing merupakan faktor perubahan naik dan turun yang konstan untuk setiap $\Delta \mathrm{t}$.

2. Peluang perubahan naik adalah $\mathrm{p}$ dan peluang harga saham turun $=1-\mathrm{p}$.

3. Secara acak kontinu, ekspektasi harga saham dengan suku bunga bebas resiko $r$, dari $S_{i}$ pada waktu $t_{i}$ menjadi $S_{i+1}$ pada waktu $t_{i+1}$ adalah:

$$
E\left(S_{i+1}\right)=S_{i} e^{r \Delta t}
$$

Model binomial $n$ langkah didapatkan dari hasil perluasan struktur model binomial satu langkah, dua langkah, tiga langkah dan empat langkah. Harga opsi tipe Eropa dapat ditentukan setelah menemukan harga saham saat jatuh tempo. Untuk menentukan harga saham pada saat jatuh tempo dibutuhkan harga saham awal $\left(S_{0}\right)$ dengan model binomial.

Pada saat jatuh tempo $T=n . \Delta t=t_{n}$ terdapat $n+1$ kemungkinan harga saham yaitu $S_{(n, j)}$ dengan dengan $j=0,1, \ldots, n$. Untuk setiap kemungkinan harga saham pada saat jatuh tempo dalam model binomial $n$-langkah dapat ditulis:

$$
S_{(n, j)}=S_{0} u^{j} d^{n-j} \text { dengan peluang }\left(\begin{array}{c}
n \\
j
\end{array}\right) p^{j}(1-p)^{n-j} \text { dengan } j=0,1, \ldots, n \text {. Nilai payoff }
$$

dari opsi saat jatuh tempo $t_{n}$ menjadi

$$
\begin{aligned}
& C_{(n, j)}=\left(S_{(n, j)}-K, 0\right) \text { untuk opsi call } \\
& P_{(n, j)}=\left(K-S_{(n, j)}, 0\right) \text { untuk opsi put }
\end{aligned}
$$
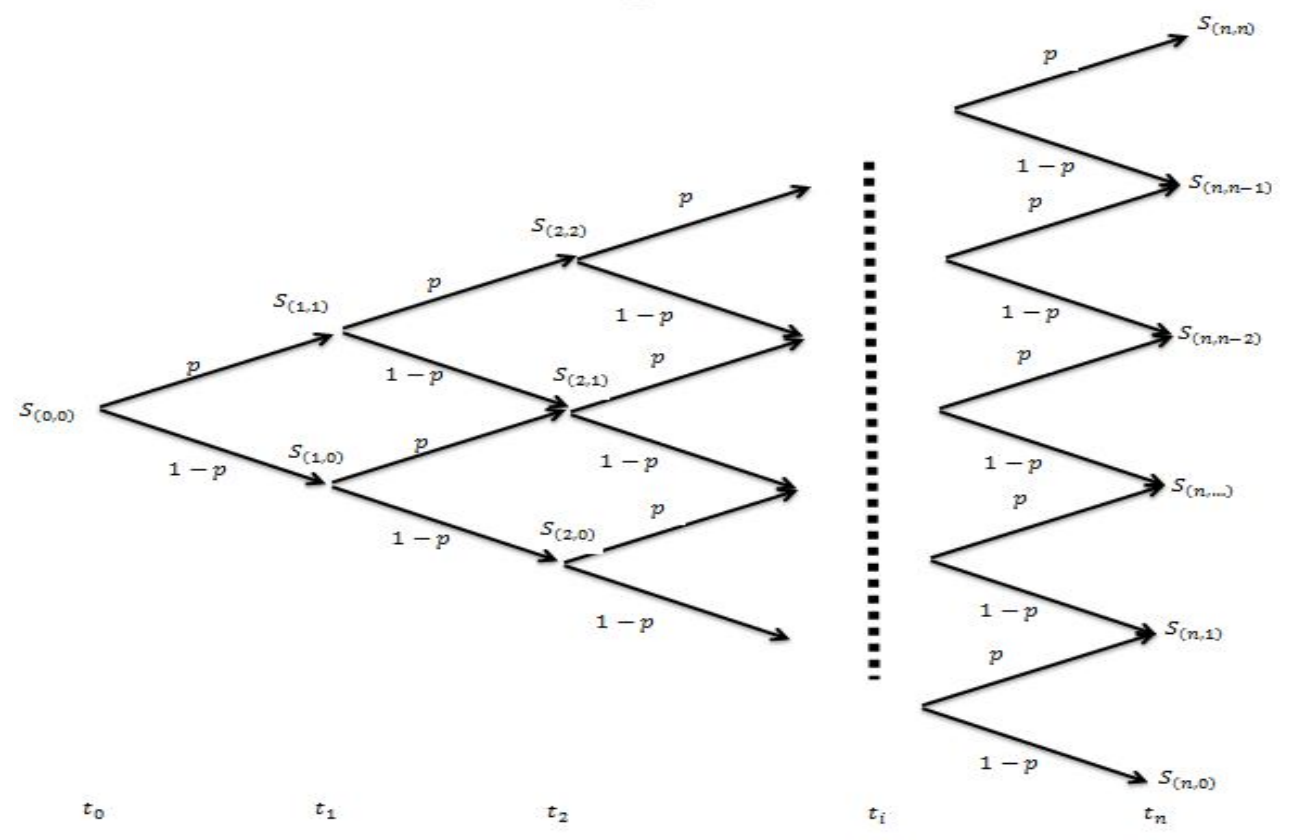

Gambar 1. Struktur Model Binomial $n$ Langkah

Nilai atau harga opsi pada saat $t_{0}$ dalam model binomial diperoleh dari nilai opsi pada saat $t_{i}$. Nilai opsi pada saat $t_{i}$ untuk opsi call $C_{(i, j)}$ merupakan nilai yang dihitung secara rata-rata dari nilai opsi pada saat $t_{i+1}$ yaitu $C_{(i+1, j)}$ dan $C_{(i+1, j+1)}$ atau dapat ditulis

$$
C_{(i, j)}=e^{-r \Delta t}\left(p C_{(i+1, j+1)}+(1-p) C_{(i+1, j)}\right)
$$

dengan $i=n-1, n-2, \ldots, 0$ dan $j=0,1, \ldots, i$. 
Begitu juga nilai opsi pada saat $t_{i}$ untuk opsi $p u t P_{(i, j)}$ diperoleh dari nilai yang dihitung secara rata-rata dari nilai opsi pada saat $t_{i+1}$ yaitu $P_{(i+1, j)}$ dan $P_{(i+1, j+1)}$ atau dapat ditulis

$$
P_{(i, j)}=e^{-r \Delta t}\left(p P_{(i+1, j+1)}+(1-p) P_{(i+1, j)}\right)
$$

dengan $i=n-1, n-2, \ldots, 0$ dan $j=0,1, \ldots, i$.

Berdasar persamaan persamaan (1) harga opsi call model binomial satu langkah dapat ditulis menjadi

$$
C=e^{-r \Delta t}\left(p C_{(1,1)}+(1-p) C_{(1,0)}\right)
$$

Berdasarkan persamaan 3 , persamaan harga opsi call model binomial dua langkah dapat ditulis menjadi

$$
C=e^{-2 r \Delta t}\left(p^{2} C_{(2,2)}+2 \mathrm{p}(1-p) C_{(2,1)}+(1-p)^{2} C_{(2,0)}\right)
$$

Untuk opsi call model binomial tiga langkah dapat dirumuskan menggunakan persamaan 3 dan 4 menjadi

$$
C=e^{-3 r \Delta t}\left(\begin{array}{c}
p^{3} C_{(3,3)} \\
+3 p^{2}(1-p) C_{(3,2)} \\
+3 p(1-p)^{2} C_{(3,1)} \\
+(1-p)^{3} C_{(3,0)}
\end{array}\right)
$$

Untuk opsi call model binomial empat langkah dapat dirumuskan menggunakan persamaan 4 dan 5 menjadi

$$
C=e^{-4 r \Delta t}\left(\begin{array}{c}
p^{4} C_{(4,4)} \\
+4 p^{3}(1-p) C_{(4,3)} \\
+6 p^{2}(1-p)^{2} C_{(4,2)} \\
+4 p(1-p)^{3} C_{(4,1)} \\
+(1-p)^{4} C_{(4,0)}
\end{array}\right)
$$

Maka diperoleh harga opsi call model binomial $n$ langkah

$C=e^{-n r \Delta t} \sum_{j=0}^{n}\left(\begin{array}{l}n \\ j\end{array}\right) p^{j}(1-p)^{n-j} \operatorname{maks}\left(S_{0} u^{j} d^{n-j}-K, 0\right)$

dimana variabel acak $j$ menyatakan jumlah kenaikan harga saham dari $n$ langkah dan $\Delta t=\frac{T}{n}$ dengan peluang terjadinya kenaikan harga saham adalah $p$ dan peluang terjadinya penurunan harga saham adalah $1-p$.

Berdasarkan Persamaan 2, persamaan harga opsi put model binomial satu langkah dapat ditulis menjadi

$$
P=e^{-r \Delta t}\left(p P_{(1,1)}+(1-p) P_{(1,0)}\right) \text {. }
$$

Berdasarkan persamaan 8, persamaan harga opsi put model binomial dua langkah dapat ditulis menjadi

$P=e^{-2 r \Delta t}\left(p^{2} P_{(2,2)}+2 \mathrm{p}(1-p) P_{(2,1)}+(1-p)^{2} P_{(2,0)}\right)$.

Untuk opsi put model binomial tiga langkah dapat dirumuskan menggunakan persamaan 8 dan 9 menjadi

$$
P=e^{-3 r \Delta t}\left(\begin{array}{c}
p^{3} P_{(3,3)} \\
+3 p^{2}(1-p) P_{(3,2)} \\
+3 p(1-p)^{2} P_{(3,1)} \\
+(1-p)^{3} P_{(3,0)}
\end{array}\right) .
$$


Untuk opsi put model binomial empat langkah dapat dirumuskan menggunakan Persamaan 9 dan 10 menjadi

$$
P=e^{-4 r \Delta t}\left(\begin{array}{c}
p^{4} P_{(4,4)} \\
+4 p^{3}(1-p) P_{(4,3)} \\
+6 p^{2}(1-p)^{2} P_{(4,2)} \\
+4 p(1-p)^{3} P_{(4,1)} \\
+(1-p)^{4} P_{(4,0)}
\end{array}\right)
$$

Maka diperoleh harga opsi put model binomial $n$ langkah yaitu

$$
P=e^{-n r \Delta t} \sum_{j=0}^{n}\left(\begin{array}{c}
n \\
j
\end{array}\right) p^{j}(1-p)^{n-j} \operatorname{maks}\left(K-S_{0} u^{j} d^{n-j}, 0\right)
$$

Keterangan:

$$
\begin{array}{ll}
C=\text { harga opsi call } & \sigma=\text { standar deviasi harga saham } \\
P=\text { harga opsi } p u t & \mathrm{p}=\text { peluang kenaikan harga saham } \\
\mathrm{S}_{0}=\text { harga saham awal } & \mathrm{u}=\text { presentase kenaikan harga saham } \\
\mathrm{K}=\text { harga kontrak saham } & \mathrm{d}=\text { presentase penurunan harga saham } \\
\mathrm{r}=\text { tingkat suku bunga } &
\end{array}
$$

\subsection{Penetuan Parameter $u, d$, dan $p$}

Berdasarkan asumsi harga saham model binomial 1 dan 2, diperoleh persamaan ekspektasi saham model diskrit.

$$
E\left(S_{i+1}\right)=p S_{i} u+(1-p) S_{i} d
$$

Dengan menyamakan ekspektasi diskrit dan kontinu didapatkan

$$
\begin{gathered}
p S_{i} u+(1-p) S_{i} d=S_{i} e^{r \Delta t} \\
p=\frac{e^{r \Delta t}-d}{u-d}
\end{gathered}
$$

Sehingga dari persamaan varian model kontinu dan diskrit

$$
\begin{gathered}
\operatorname{Var}\left(S_{i+1}\right)=\operatorname{Var}\left(S_{i+1}\right) \\
S_{i}{ }^{2}\left[p(u-d)^{2}-p^{2}(u-d)^{2}\right] \\
=S_{i}{ }^{2} e^{2 r \Delta t}\left(e^{\sigma^{2} \Delta t}-1\right)
\end{gathered}
$$

Didapat parameter $=\beta+\sqrt{\beta^{2}-1}, d=\frac{1}{u}$ dengan $\beta=\frac{e^{-r \Delta t}+e^{\left(r+\sigma^{2}\right) \Delta t}}{2}$.

\subsection{Perbandingan Harga Opsi Binomial dengan Harga Opsi Pasar dan Harga Opsi Model Black-Scholes}

Simulasi saham yang digunakan untuk menentukan harga opsi tipe Eropa model binomial $n$ langkah dengan menggunakan software matlab pada penelitian ini disajikan pada Tabel 1 . Berdasarkan perbandingan harga opsi yang dihasilkan oleh model binomial dan model BlackScholes pada beberapa saham pada tabel 2 dan 3 dapat dilihat bahwa harga opsi yang dihasilkan oleh model binomial lebih baik daripada harga opsi yang dihasilkan model Black-Scholes apabila keduanya dibandingkan dengan harga opsi pasar. Dilihat dari besar erornya, penentuan harga opsi dengan model binomial memberikan harga yang lebih mendekati harga opsi pasar dibandingkan dengan besar eror yang dihasilkan dari harga opsi model Black-Scholes terhadap 
harga opsi pasar. Walaupun hasil perhitungan harga opsi model binomial dengan hasil perhitungan harga opsi model Black-Scholes hampir sama atau tidak jauh berbeda.

Tabel 1. Daftar Harga Saham

\begin{tabular}{lccccl}
\hline Nama Saham & $T$ & $\sigma$ & $r$ & $\left(S_{0}\right)$ & $(K)$ \\
\hline CAT & $\frac{1}{12}$ bulan $=0,0833$ & 0,3125 & 0,025 & 135,15 & 135 \\
DIS & $\frac{1}{12}$ bulan $=0,0833$ & 0,220 & 0,025 & 140,40 & 140 \\
AAPL & $\frac{1}{12}$ bulan $=0,0833$ & 0,2973 & 0,025 & 200,67 & 215 \\
TSLA & $\frac{1}{12}$ bulan $=0,0833$ & 0,5869 & 0,025 & 238,69 & 237,50 \\
FB & $\frac{1}{12}$ bulan $=0,0833$ & 0,378 & 0,025 & 194,41 & 180 \\
\hline
\end{tabular}

\begin{tabular}{lccccc}
\multicolumn{6}{l}{ Tabel 2. Perbandingan Harga Opsi Call Model Binomial dan Model Black-Scholes dengan Harga Opsi Pasar } \\
\hline Nama & Model & Model Black- & Opsi & Eror Binomial-Opsi & Eror Black Scholes-Opsi \\
Saham & Binomial & Scholes & Pasar & Pasar & Pasar \\
\hline CAT & 5,04263 & 5,07200 & 3,91 & 1,13263 & 1,16200 \\
DIS & 3,89953 & 3,90348 & 3,70 & 0,19953 & 0,20348 \\
AAPL & 2,21695 & 2,21707 & 1,82 & 0,39695 & 0,39707 \\
TSLA & 16,8589 & 16,9098 & 16,1 & 0,7589 & 0,8098 \\
FB & 17,5421 & 17,5737 & 17,03 & 0,5121 & 0,5437 \\
\hline
\end{tabular}

Tabel 3. Perbandingan Harga Opsi Put Model Binomial dan Model Black-Scholes dengan Harga Opsi Pasar

\begin{tabular}{cccccc}
\hline Nama & Model & Model Black & Opsi & Eror Binomial-Opsi & Eror Black Scholes-Opsi \\
Saham & Binomial & Scholes & Pasar & Pasar & Pasar \\
\hline CAT & 4,61179 & 4,64116 & 4,63 & 0,01821 & 0,00116 \\
DIS & 3,20828 & 3,21223 & 3,90 & 0,69172 & 0,68777 \\
AAPL & 16,0997 & 16,0998 & 13,2 & 2,8997 & 2,8998 \\
TSLA & 15,1748 & 15,2257 & 15,15 & 0,0248 & 0,0757 \\
FB & 2,75767 & 2,78922 & 1,32 & 1,43767 & 1,46922 \\
\hline
\end{tabular}

\section{SIMPULAN}

Harga opsi call tipe Eropa model binomial $n$ langkah adalah $C=e^{-n r \Delta t} \sum_{j=0}^{n}\left(\begin{array}{l}n \\ j\end{array}\right) p^{j}(1-p)^{n-j}$ maks $\left(S_{0} u^{j} d^{n-j}-K, 0\right)$. Harga opsi put tipe Eropa model binomial $n$ langkah yaitu $P=e^{-n r \Delta t} \sum_{j=0}^{n}\left(\begin{array}{c}n \\ j\end{array}\right) p^{j}(1-p)^{n-j}$ maks $\left(K-S_{0} u^{j} d^{n-j}, 0\right)$ dimana variabel acak $j$ menyatakan jumlah kenaikan harga saham dari $n$ langkah dan $\Delta t=\frac{T}{n}$ dengan peluang terjadinya kenaikan harga saham dan penurutan harga saham berturut-turut adalah $p$ dan $1-p$. Parameter $p=\frac{e^{r \Delta t}-d}{u-d}, u=\beta+\sqrt{\beta^{2}-1}, d=\frac{1}{u}$ dengan nilai $\beta=\frac{e^{-r \Delta t}+e^{\left(r+\sigma^{2}\right) \Delta t}}{2}$.

Hasil perbandingan menunjukkan bahwa model binomial lebih baik daripada model Black-Scholes. Dilihat dari besar erornya, penentuan harga opsi dengan model binomial memberikan harga yang lebih mendekati harga opsi pasar dibandingkan dengan besar eror yang dihasilkan dari harga opsi model Black-Scholes terhadap harga opsi pasar. Namun secara empiris, perbandingan harga opsi yang dihasilkan oleh model binomial tidak jauh berbeda atau hampir sama dengan harga opsi yang dihasilkan oleh model Black-Scholes yang merupakan model yang telah banyak diterima di dunia keuangan.

Hasil penelitian ini menggunakan saham yang tidak membagikan deviden dikarenakan dalam penelitian ini dilakukan perbandingan terhadap harga opsi model Black-Scholes yang 
72 | Via Maulida, Emy Siswanah, Eva Khoirun Nisa - Penentuan Harga Opsi Tipe Eropa dengan Model Binomial

hanya dapat berlaku untuk saham yang tidak membagikan deviden. Untuk penelitian selanjutnya disarankan untuk menentukan harga opsi tipe Eropa model binomial yang membagikan deviden dikarenakan deviden lebih menguntungkan bagi investor.

\section{DAFTAR PUSTAKA}

Agustina, Fitriani. (2009). Kekonvergenan Model Binomial dalam Penentuan Opsi Eropa. Prosiding Seminar Nasional Matematika. Bandung.

Aziz, Abdul. (2009). Empat Model Aproksimasi Binomial Harga Saham Model Black-Scholes. Chauchy. 1(1): 1-10.

Hull. John C.. (2012). Option Futures and Other Derivatives. South Westren College Pub.

Judokusumo, Suherdi. (2007). Pengantar Derivatif dalam Moneter Internasional. Jakarta: Grasindo.

Siahaan, Hinsa. (2008). Seluk-Beluk Perdagangan Instrumen Derivatif. Jakarta: PT Elex Media Komputindo Kompas Gramedia.

Tandelilin, Eduardus. (2017). Pasar Modal Manajemen Portofolio \& Investasi. Sleman: PT Kanisius. 